Flores Avalos, Martha Isabel.

Marti, Sandra Amelia.

Profesoras investigadoras de la Universidad Autónoma Metropolitana Unidad Xochimilco México, Área de Procesos Creativos

y Comunicación en el Arte y el Diseño. Departamento de Síntesis Creativa, División de Ciencias y Artes para el Diseño.

\title{
La dialéctica en la urbe y la producción en el arte y el diseño. Perspectiva y prospectiva.
}

\section{The dialectic between the city and the production in the art and the design. Perspective and prospective.}

\author{
TIPO DE TRABAJO: \\ Comunicación. \\ PALABRAS CLAVE: \\ Espacio urbano, dialéctica, arte, diseño.
}

KEY WORDS:

Urban Space, dialectics, art, design.

RESUMEN.

Presentamos el estado del arte del proyecto "La dialéctica entre la urbe y la producción en el arte y el diseño. Perspectiva y prospectiva", que se plantea como un espacio de investigación sobre el ambiente urbano y los procesos creativos en el ámbito de la producción de obras de arte y de diseño. Entiéndase éste como el espacio y el tiempo de la ciudad en el que interactuamos y generamos reflexiones en torno a esta convivencia. Surge el interés en investigar a los productos pero también a los sujetos, los procesos poniendo énfasis en la propia interacción en este ámbito de muchas gamas. Visualizamos a la ciudad como un elemento vivo en permanente movimiento, de ahí a la idea de la dialéctica que gira en torno a la urbe y a la manifestación artística y del diseño.

\begin{abstract}
Las autoras hemos participado en diversas actividades conjuntando intereses académicos y profesionales; compartimos el gusto por el estudio de los fenómenos culturales en el espacio urbano y sus manifestaciones. Producimos obra tanto de diseño como artística en distintos medios pero también nos interesa mucho el trabajo de reflexión en torno a nuestros procesos y de otros autores. De 2008 a 2010 participamos activamente en el Seminario doctoral de Estudios Urbanos en la Universidad Autónoma Metropolitana en la Unidad Azcapotzalco, "La ciudad de la Imagen". A partir de esa experiencia hemos elaborado mucho trabajo conjunto: ponencias y ensayos para diversas revistas y foros de temas afines, vinculación con la docencia y la obra artística. Sandra Martí ha desarrollado la figura de "Besadora de ciudades", en el performance principalmente. Martha Flores ha desarrollado la figura del "Flâneur por la ciudad", en obra gráfica. En este foro deseamos enfatizar el trabajo de producción artística y la reflexión del proceso creativo.
\end{abstract}

\section{ABSTRACT.}

We present the state of the art of the project "The dialectic between the city and the production in the art and the design Perspective and prospective", that arises as a space of investigation on the urban environment and the creative processes in the field of the production of works of art and of design. Understand this as the space and time of the city in which we interact and generate reflections around this coexistence. The interest in investigating the products but also the subjects, the processes emphasizing the own interaction in this area of many ranges. We visualize the city as a living element in permanent movement, from there to the idea of the dialectic that revolves around the city and the artistic and design manifestation. The 
authors have participated in various activities combining academic and professional interests; we share a taste for the study of cultural phenomena in the urban space and its manifestations. We produce works of both design and art in different media but we are also very interested in the work of reflection on our processes and other authors. From 2008 to 2010 we actively participated in the PhD Seminar on Urban Studies at the Metropolitan Autonomous University in the Azcapotzalco Unit, "The city of the Image". Based on this experience, we have done a lot of joint work: presentations and essays for various journals and forums on related subjects, links with teaching and artistic work. Sandra Martí has developed the figure of "Kisser of cities", in the performance mainly. Martha Flores has developed the figure of "Flâneur by the city", in graphic work. In this forum we want to emphasize the work of artistic production and the reflection of the creative process.

\section{CONTENIDO.}

\section{INTRODUCCIÓN.}

En 2007 nos conocimos en la Universidad Autónoma Metropolitana como docentes. En 2008 empezamos a trabajar en el Seminario "La ciudad de la Imagen" en UAM-Azcapotzalco como trabajo de posgrado. A partir de 2012 empezamos un viaje de investigación compartida dentro de la figura de profesoras-investigadoras. Veníamos del campo de las artes plásticas y del diseño gráfico. Hemos trabajado nuestras vidas artísticas profesionales en paralelo. Y el interés continuo por la investigación artística en el espacio urbano nos une.

Investigar es perseguir el proceso del conocimiento. Y consideramos el proceso del conocimiento y la investigación, como traducción o construcción intersubjetiva entre quien investiga y lo investigado, un proceso de interpretación y re-interpretación, donde quien observa influye en lo observado y viceversa. Nuestras coordenadas espacio-temporales nos guían en el presente avance, el cual se organiza como mosaico de diversos productos de trabajo: ensayos, presentaciones, obra gráfica presentada en exposiciones; que van amalgamando el corpus de esta investigación colectiva. Se pretende que con estos avances podamos organizar un espacio de reflexión que incluye varias manifestaciones resultado de observar e interpretar la ciudad y ubicar el nodo dialéctico de las diversas relaciones que se van conformando y descubriendo. Las líneas de investigación que nos atraen giran en torno a: ciudad y cuerpo, género, trayectos, espacio público, arte, espacio íntimo, espacio virtual, diseños y cultura.

A continuación presentamos algunas de las premisas de la producción artística en el contexto de la investigación que realizamos, entendiendo las múltiples relaciones dialécticas entre la urbe y la producción en el diseño y en el arte desde una perspectiva fenomenológica:

Premisa 1. Motivador del proceso creativo: La ciudad está pensada para desarticular el nomadismo. Pero el individuo se enfrenta a otro nomadismo en la ciudad para identificar lo que ha creado. Todo esta dado para ser sedentario. Se pone en tela de juicio el confort. La supuesta comodidad se pierde por que se presenta la sensación de hastío. El arte nos da una opción para reinventarnos.

Premisa 2. Energía en estado de torrente. Punto en común. Emoción promueve la energia. Emoción al encontrarnos con el factor sorpresa. Muchas de las actividades, aún planeadas, pueden generar detalles inesperados. La sorpresa es un excelente motivador, motor que permite que las cosas sucedan. Aún con guión no hay nada certero hasta que sucede. Parte del plan o del no plan.

Premisa 3. De la dislocación a la colocación: Otro giro en la investigación de procesos creativos. De la descripción de los hechos al proceso creativo: motivadores, causas, sensaciones en el transcurso de ese hacer. Del caos al orden o del orden al caos, y contínuamente. Este es el proceso creativo. Este es el proceso dialéctico, resiliente y reparador que construye para destruir y de la destrucción se crea.

\section{DESARROLLO.}

\section{Sandra Martí.}

Besadora de Ciudades $^{1}$ es un proyecto que incorpora la dimensión espacial y afectiva compartiendo a la corporalidad desde su materialización a partir de una ruptura de rutina. Esto supone asumir que el cuerpo existe por afuera de las prácticas que lo hacen posible de alguna manera determinada. Es una óptica de corte performativo porque se recupera el cuerpo en estado afectivo fuera del conjunto de marcos normativos que suponen disciplinamientos, y también puede entenderse como un conjunto de emplazamientos espaciales, producidos por estas prácticas corporales.

\footnotetext{
${ }^{1}$ Besar la ciudad es un proyecto compartido con la artista María José Gorozo, creado en CDMX, en el año 2011. Por momentos se incorpora a la reflexión feminista al proponer otros procesos y modos de recorridos del cuerpo femenino por la ciudad.
} 
Es este un proyecto basado en la acción de caminar, sentir y recorrer espacios, arrojando pequeñas huellas referenciales (besos) en sitios tan disímbolos como gráficas de la calle, lugares y objetos del mobiliario urbano, que despierten algún interés en particular, o bien paseos que tengan vida propia y que se materializan en creación de imágenes-besos que captan las emociones suscitadas por los distintos ambientes. En este ejercicio existen tres constantes de desarrollo: el beso, la ciudad y la acción de recorrer la ciudad.

Por ello, en comunión con el concepto de recorridos afectivos, desde hace años he realizado el presente proyecto en algunos espacios de ciudades mexicanas, lo mismo en la CDMX (Coyoacán, la Roma, Centro Histórico, Iztapalapa), que en Durango, Tijuana, Aguas Calientes, Mérida, Puebla... o bien en otras ciudades como La Habana (Cuba), Mendoza (Argentina) y Santiago (Chile). Las ciudades recorridas, entonces, se convierten en trama de mi historia personal. Soy la catalizadora de cómo recreo y siento distintos microespacios y, por momentos, ellos son mi entorno, receptáculo de propios intereses para ejercitar un aprendizaje "artístico-creativo" que conduce a descubrir y re-construir afectivamente cada lugar.

En ésta investigación propongo que mi cuerpo sienta en estado afectivo. Cada ciudad presenta una serie de códigos muy distintos a la hora que un cuerpo-mujer la recorre; entonces propongo la vivencia del entorno urbano a través de una experiencia artística; es decir, como un encuentro estético, donde se establezca una relación de intercambio recíproco entre la ciudad y el vivir: vivir el espacio urbano como proceso creativo, entendiendo al espacio en continua interacción física y psicológica. Así percibo el espacio, la arquitectura, las modulaciones de la luz, los sonidos de la urbe, ingresando a un estado de alerta atemporal creando perfomativamente mi recorrido.
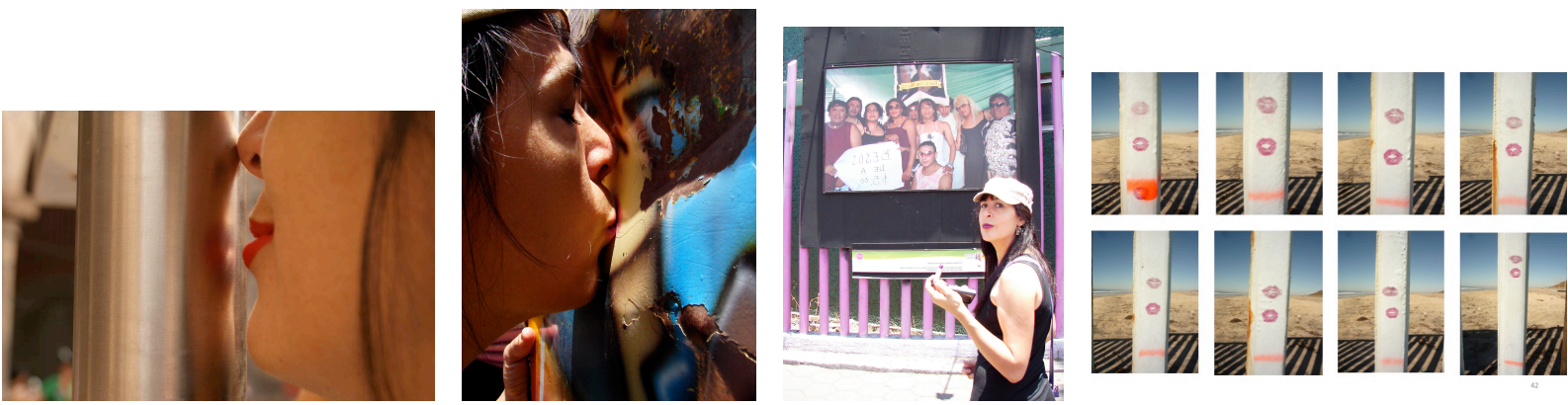

Aca observamos imágenes archivo del proyecto (México: 1 Coyoacán, 2-3 Iztapalapa, 4 Tijuana) el cual es una práctica poética donde el estar y hacer del cuerpo, puede ser comprendido como un ejercicio de libertad ciudadana. Deviene entonces una búsqueda de emociones desconcertantes mediante la desorientación del paseo. Como paseante percibo a través del sentido visual, el olfativo y el táctil consumado en la cercanía íntima que se establece al besar los espacios como pedazos de un cuerpo-ciudad. Mis ojos y mi boca tocan las tersuras y rugosidades, las superficies accidentadas y los colores de los muros, las texturas del tiempo, los aromas y estados matéricos. Por ello es una vivencia íntima, subjetiva, exclusiva e individual, ya que al besar las superficies de los muros siento que juego, a la vez que permito afloren miedos, seguridades, atrevimientos y sensaciones táctiles.

El beso se logra y se plasma por medio de considerar a mis propios labios como una plantilla: labios pintados con rouge para plasmar pequeñas huellas de besos en las superficies. Considero este dibujo personal como expresión de afecto, rito, interrelación y amor para con los espacios y mi persona. Mis labios, a modo de foco sensitivo, colaboran en sumar información e identificación con el entorno. Por lo tanto, el lugar seleccionado queda intervenido con un beso rojo o de otros colores, o conjuntos de besos, o besos que intervienen gráficas o dibujos ya existentes, inclusive algunos plasmados por otros artistas urbanos, sin desdeñar (sino más bien sumando) formas, texturas o trazas propias de la arquitectura o el mobiliario urbano.

Ese (este) estar aquí "besando espacios" es el relato de la experiencia que contribuye a la significación de los lugares de mi memoria trascendiendo las propias normatividades del/mi cuerpo. Es fuente de sentido de mi presente urbano, como cuerpo articulado, actuante, expresivo. Soy receptora y a la vez productora de espacio. Entonces me percibo como generadora de memoria (alegría, dolor, sentimiento, límite, humor) y también dispositivo de sentimiento, experiencia y narración.

\section{Martha Flores.}

El "Flâneur por la ciudad", en obra gráfica. Hablo en primera persona. A partir de la observación de la ciudad, mi primera aproximación sensible ha surgido del interés por la etnografía urbana como una herramienta para la captura de sensaciones. Lanzarte a la calle y ser el observador que captura las sensaciones que se presentan. Voy recabando información, capto imágenes de todo tipo: visuales, tactiles, sabóricas, audibles; entonces mi memoria adquiere una importancia especial: lo que no puedo capturar lo almaceno en mi base de datos sensible. Los datos pueden ser los apuntes tanto descriptivos como bocetarios, o palabras clave para no olvidar una idea, los recuerdos por supuesto, las fotografías, los sonidos ya sea atrapados o recordados. La idea de la traza en una ruta sensible. Posteriormente trato de identificar los hallazgos que han llamado más mi atención. A partir de ahí empiezo a hacer la selección. 
Organizo y jerarquizo, armo categorías. Generalmente ya existe un tema previo que ayuda a que la búsqueda sea selectiva. $\mathrm{O}$ bien dependo de un lugar en específico y trato de sacar la esencia de dicha experiencia. Muchas veces los materiales son suficientes, pero otras es necesario apelar a la memoria como parte del ejercicio creativo. Siempre es un proceso interpretativo que requiere de todos los recursos posibles. Los trayectos de toda índole se convierten en la materia prima por excelencia: pueden ser trayectos locales que se reproducen diariamente lo cual va generando la traza de lo cotidiano, o bien pueden ser trayectos de visitas a lugares nuevos que en una primera y única aproximación dan cuenta de una experiencia original. A mí me interesan los microtrayectos, las trazas mínimas, las pequeñas experiencias que pueden o no ser acumulativas. Me interesan las primeras experiencias. Y de ahí a la producción.
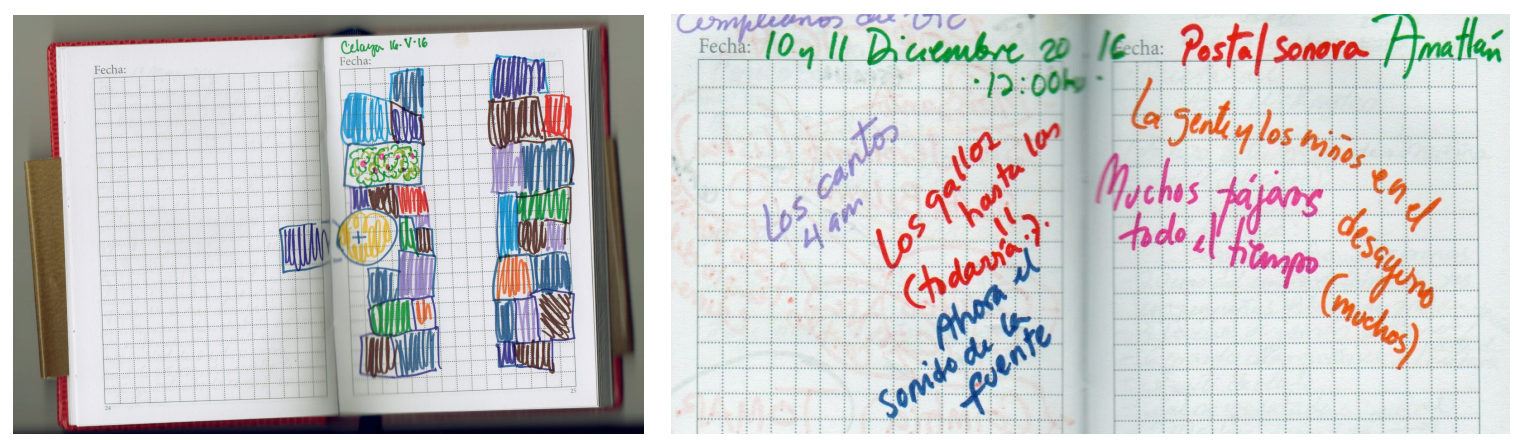

llustración 1 y 2. Ejemplos de registros, traza de la ciudad de Celaya y postal sonora escrita en el pueblo de Amatlán.

Vivo en la Ciudad de México, una de las mega urbes más complejas del mundo. Tal vez no la más sobrepoblada pero posiblemente ya la más contaminada. Aunque todavía por las mañanas puedo escuchar los cantos de los pájaros y ver el sol y las buganvillas. En esta ciudad casi siempre hay una obra en construcción. Hacer deshacer quizás reftificar lo que no salió bien, quizás acostumbrándonos a vivir en el "casi acabo" o en el "mientras tanto", o "en vez de...". Siempre viviendo las temporalidades, siempre con una illusion de que algún día por fin van a terminar los hoyos en las calles. A continuación presento un ejemplo de un microtrayecto de una hora aproximadamente por el modo del "flâneur en automóvil": es un trayecto que realizo aproximadamente dos veces al mes. Empieza en la zona sur de la ciudad de México y termina en el Poniente, a través de una vía muy importante a la que llamamos el "Anillo Periférico" ${ }^{2}$. Y es una vía rápida que efectivamente da vueltas a la periferia de la Ciudad de México y zona conurbada. Lo que yo hago es un trayecto medio en comparación con todo el recorrido que se puede hacer en esta gran vía. Según datos tiene una longitud total de $58.83 \mathrm{kms}$. Observo, si puedo tomo fotos, luego, al llegar a mi lugar de trabajo doy cuenta mediante un dibujo la sensación del trayecto, y luego lo comparo con lo que indica el google maps, y para mi sorpresa doy cuenta de que la traza algo se parece a lo que indica la tecnología, pero nunca nada se compara con la traza de sensaciones. En otra etapa retomo fotografías del trayecto y elaboro imágenes .
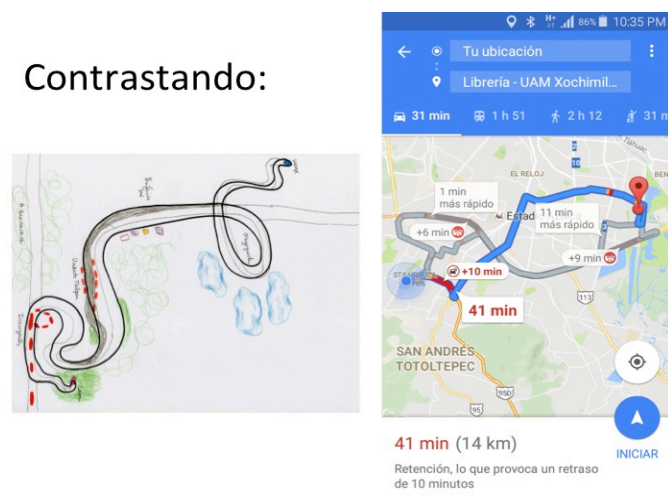

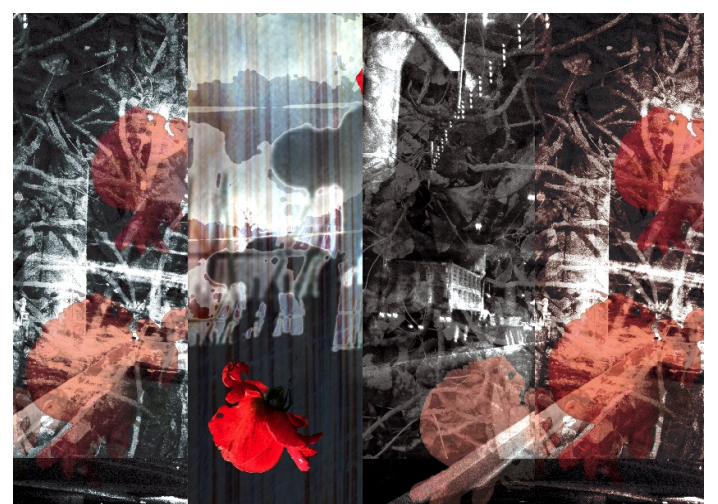

Ilustración 3 y 4 Recorridos de la memoria y contraste con googlemaps e intervención gráfica "Megalópolis 2016"

\footnotetext{
2 "Cuando se habla de un tránsito urbano de largo recorrido que otorga amplia conectividad a la ciudad, se está considerando a vialidades que tienen una función principal en la distribución de dicho tránsito, como el Anillo Periférico y el Circuito Interior, también definidas como vías anular." Del texto "Vialidades, las venas de la ciudad", de SETRAVI (Secretariía de transportes y vialidad) del 27 de Julio de 2009. Autor descononido. http://web.archive.org/web/20090727075031/http://www.setravi.df.gob.mx/reportajes/r_vialidades.html. Revisado el 10 de Marzo de 2017.

${ }^{3}$ Obra gráfica realizada en el contexto del colectivo de trabajo gráfico "Sin-tesiS".
} 


\section{CONCLUSIÓN.}

Se ha pretendido reflexionar sobre una manera alternativa de reconocer y registrar ciertos espacios de la ciudad, y para ello ha sido necesario hacer uso de metodologías y técnicas de investigación nacidas en diferentes disciplinas ensambladas creativa y flexiblemente con otras, en lo que bien puede denominarse un "pluralismo metodológico". No obstante la metodología del flanear, es la preferida, ya que es una actitud vital, abierta y sin prejuicio; es una actividad dialógica flâneur-lugar, en la cual existe una interrelación que permite un reconocimiento mutuo, un permitirse y compartirse. Es una disposición especial que ocurre en el momento en el que el flâneur puede activarse, lo cual refiere a una especie de vivencia experimental entre el sujeto (caminante, conductor o besante) y el objeto (ciudad, zona urbana, espacio público, periferia).

Agreguemos igualmente que, a pesar de que suele existir una hegemonía de la visión en cuanto a la percepción de la ciudad, cada paseo es una experiencia significativa multisensorial. $Y$ en específico en estos proyectos preponderan las sensaciones ideadas, haciendo que la experiencia urbana sea emancipadora, rebelde, apasionante e intensa. Por ello, la percepción de nuestra ciudad interior, es posteriormente una percepción artística. La ciudad, por tanto, se convierte en un fondo que actúa como soporte de las actividades suspendidas entre las certezas y la incertidumbre, la fe y la duda, la confianza y la locura. La ciudad paseada, observada, besada o recorrida es para re-inventar y recrear el concepto del flâneur. Es, por tanto, de este modo como vivimos, investigamos y decodificamos la posible atmósfera anímica de la urbe, tendiendo a reflexionarla amorosa, espontánea, sorprendidas y lúdicamente.

Éstas formas de explorar el paseo o el recorrido como práctica estética, nos permite bosquejar una dimensión cognitiva, buscando o detectando los signos y huellas invisibles que se dejan encontrar y descifrar. Tras ambas perspectivas autorales, pensamos que el arte y el diseño colaboran a pensar la ciudad en prospectiva. Ya que pretendemos vaticinar, cómo es que podríamos mejorar las condiciones del ámbito urbano, proponiendo proyectos y metodologías como manera de escucharnos y escuchar al otro.

\section{FUENTES REFERENCIALES.}

Calvino Italo, Las ciudades invisibles, Madrid, Siruela, 1994.

Cruces Francisco, "Performances urbanas", en Miguel Ángel Aguilar Díaz et al. (coords.), Pensar lo contemporáneo: de la cultura situada a la convergencia tecnológica, Barcelona, Anthropos/Universidad Autónoma Metropolitana-Iztapalapa, 2009.

Miguel Ángel Aguilar y Paula Soto Villagrán, Cuerpos, espacios y emociones: aproximaciones desde las ciencias sociales, México, Universidad Autónoma Metropolitana-Iztapalapa/Porrúa, 2013.

McDowel Linda, Género, identidad y lugar: un estudio de las geografías feministas, Madrid, Cátedra, 2000. 